\title{
Enhancing the Power Tracking Method in Hybrid System using Artificial Neural Network Integrated with Fuzzy Controller
}

\author{
J. Karthika ${ }^{1}$, M. Rajkumar ${ }^{2}$, A. Radhika' and S. Sivaranjani' ${ }^{1}$ \\ 'Department of EEE, Sri Krishna College of Engineering and Technology, Coimbatore - 641008, Tamil Nadu, India; \\ karthika@skcet.ac.in, radhika@skcet.ac.in, sivaranjanis@skcet.ac.in \\ ${ }^{2}$ Department of IT, Sri Krishna College of Engineering and Technology, Coimbatore - 641008, Tamil Nadu, India; \\ rajkumarm@skcet.ac.in
}

\begin{abstract}
Objective: To search a point where huge amount of power can be coerced from hybrid system under continuously varying environmental conditions. Methods/Statistical Analysis: Artificial Neural Network integrated with Fuzzy Controller (ANFIS) is proposed to enhance the power tracking method in Hybrid System. This mode of extracting maximum power is highly accurate and it is highly adopted for eco- friendly changes. Due to fast tracking of maximum power, the overall efficiency is highly increased. The projected system has very less settling time and very low overshoot. Findings: This study contributes to a controller design using ANFIS for rapid tracking of maximum power in hybrid system. Application: This controller can be used in all renewable energy based hybrid system which has become a popular electrical energy source. The performance is upgraded by settling time, overshoot and accuracy.
\end{abstract}

Keywords: ANFIS Controller, MPPT, Solar PV Array, Wind Turbine

\section{Introduction}

In isolated areas, the mode of power generation is different from the conventional form of electrification. The power supply is provided by thermal power plants, commonly diesel generators. But the cost of generation is very high. By combining several energy sources hybrid power system can provide the best economical and reliable solution for many applications. Maximum power tracking methods ${ }^{1-3}$ were suggested for solar and wind in both grid connected as well as standalone systems. The implementation of $\mathrm{P}$ and $\mathrm{O}$ method is easy. But, at maximum power there will be oscillations at the steady state condition which leads to the waste of power. Hence improved $\mathrm{P}$ and $\mathrm{O}$ methods are proposed to lessen fluctuations at stable state. But it decelerates the speed of response. IncCond method has downside in decision making. The tracking speed increases in proportion to the error's step size. But, larger error step size will habitually decreases the efficiency of tracking the MPP. The Neural Network ${ }^{4,5}$ is yet another best method used for representing the input-output relationship of the system. It does not require in depth understanding about the system, whereas fuzzy logic control entails it. Fuzzy can change linguistic and heuristic terms into arithmetical values by using membership functions and fuzzy rules ${ }^{6,7}$. This intelligent Adaptive Neuro-fuzzy Inference System (ANFIS) controller integrates the benefits of neural and fuzzy. Hence, this method is most significant to deal with the non-linear systems. Therefore, in this research, ANFIS based intelligent controller is designed and proposed to acquire the maximum available at all specified environmental conditions.

\section{Maximum Power from Solar}

\subsection{Fuzzy based MPPT}

The fuzzy model with Mamdani Inference System was designed for the rating of $3 \mathrm{~kW}$ solar PV array. Triangular membership functions along with a set of 49 rules are designed. The error signal is given as inputs and the out- 


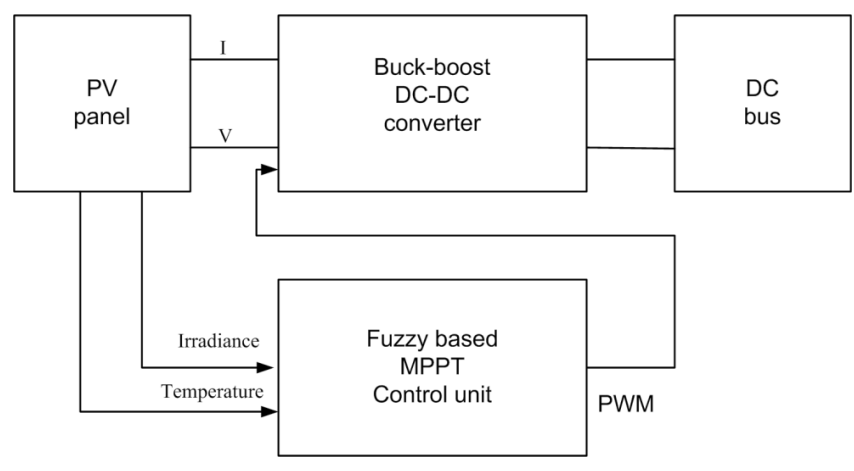

Figure 1. Solar PV model.

put signal (firing angle) is given to the converter. This will enhance the power flow control and voltage profile.

Figure 1 shows PV model with fuzzy based maximum power. The error signal of the voltages is given to the fuzzy system. It then infers the control signal from the rule base provided and gives the appropriate excitation voltage, to damp the oscillations.

\subsection{ANFIS based MPPT}

The MPP technique by design is used to determine the optimum voltage at which the PV module should operate. The optimum voltage is for a particular temperature and irradiance values. The ANN is trained to identify the input-output relationships of various parameters. The developed PV model is used to collect the training data to train the network. The operating temperature ranges $15^{\circ} \mathrm{C}$ to $60^{\circ} \mathrm{C}$. The solar irradiation level ranges $100 \mathrm{~W} / \mathrm{m}^{2}$ to $1000 \mathrm{~W} / \mathrm{m}^{2}$. The value of maximum power is documented for the various pairs of temperature and irradiance levels. Figure 2 shows the proposed ANFIS controller for MPPT.

The proposed ANFIS uses Sugeno inference mechanism. The main reason for the use of Sugeno inference mechanism is its ability to model non-linear problems. In this type of inference mechanism, output is a function of inputs and is a fuzzy singleton. Figure 3 is a screen shot of the ANFIS editor. It shows a plot of the training error values. The ANFIS is generated with grid partitioning fuzzy inference mechanism, where each input is assigned with seven membership functions and then trained for 20,000 epochs (number of iterations for training) using hybrid learning rule. Figure 4 shows the representation of ANFIS with Sugeno inference system. Figure 5 shows the structure of ANFIS and parameters used in its execution process. In Figure 5 'input' represents the inputs which are solar irradiance and panel temperature.
The proposed ANFIS controller reduces the settling time and overshoots in the system. This will enhance the system performance when compared to the conventional controllers and is proved in Table 1.

\section{Maximum Power from Wind}

\subsection{Fuzzy based MPPT}

The fuzzy model with Mamdani Inference System was designed for $8 \mathrm{~kW}$ wind system.

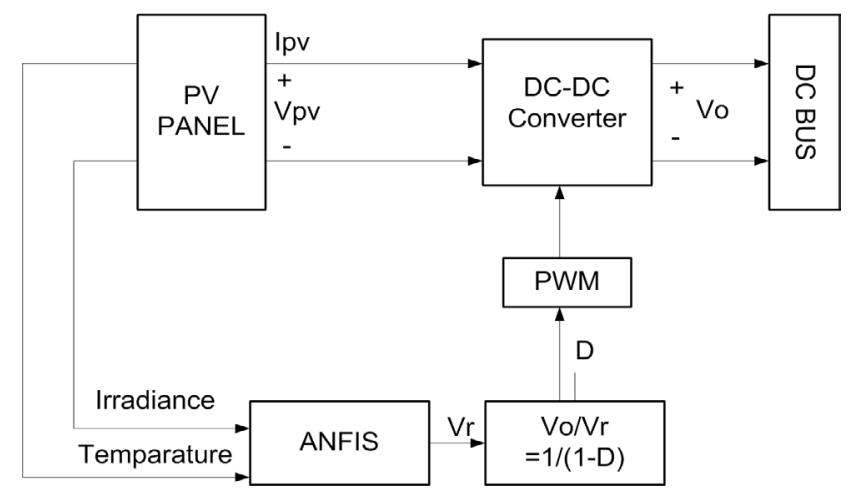

Figure 2. Proposed ANFIS controller for MPPT.

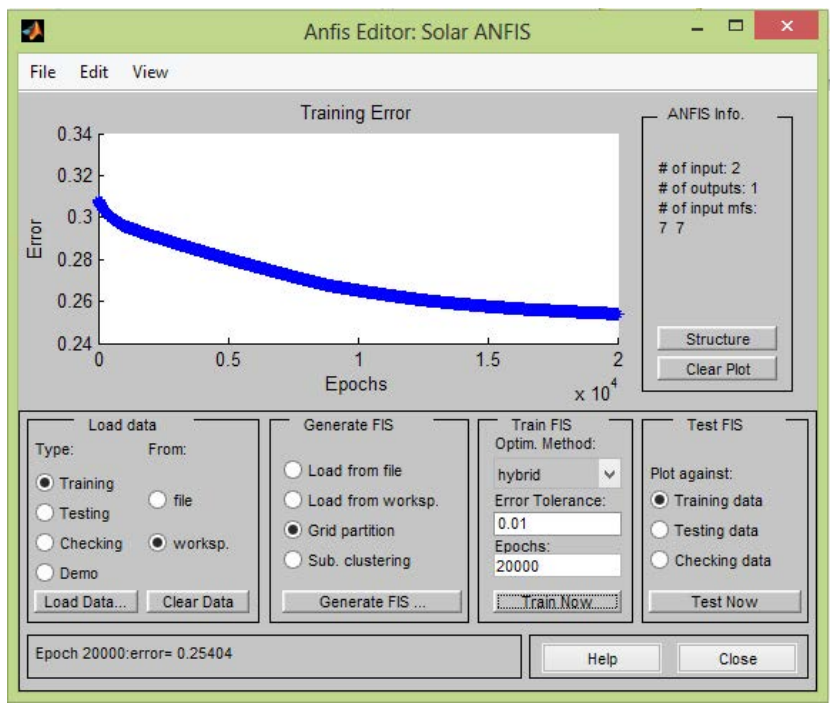

Figure 3. A screen shot of ANFIS editor for PV model.

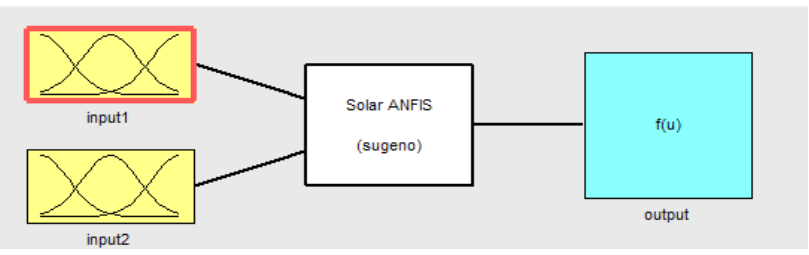

Figure 4. A block representation of ANFIS for solar. 


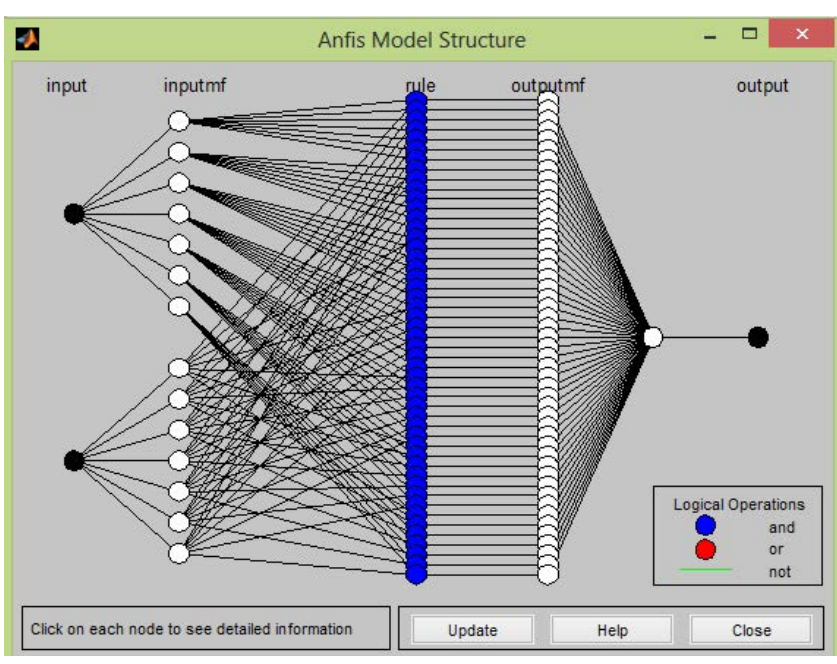

Figure 5. Structure of ANFIS for solar.

Table 1. Output power with conventional PI, fuzzy and ANFIS controllers

\begin{tabular}{|l|l|l|l|}
\hline Parameter & PI & FUZZY & ANFIS \\
\hline Peak Overshoot (\%) & 25.9 & 17.8 & 1.4 \\
\hline Settling Time (seconds) & 0.7 & 0.58 & 0.35 \\
\hline
\end{tabular}

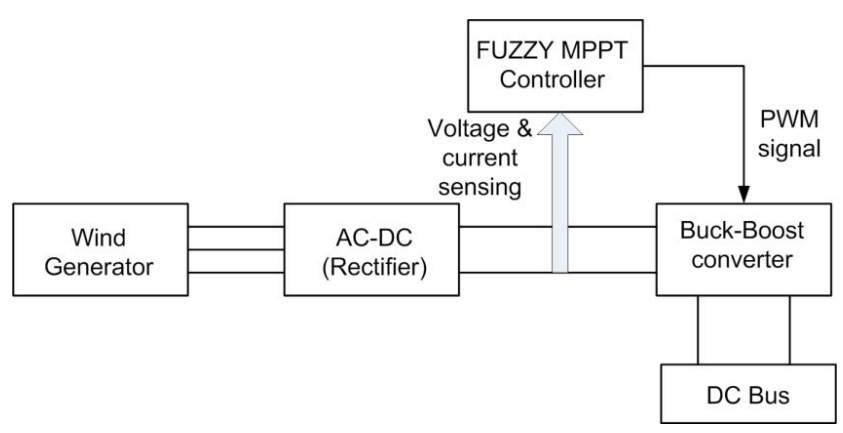

Figure 6. Fuzzy controller for wind.

Fuzzy based MPPT controller for wind system is shown in Figure 6. Triangular membership functions along with a set of 49 rules are designed. The error signal is given as inputs and the output signal is given to buckboost converter. This will enhance the voltage profile and power flow control of the wind system.

\subsection{ANFIS based MPPT}

The proposed MPPT is shown in Figure 7. By controlling the duty ratio of generating part converter the maximum power can be extracted. An indirect approach given in Figure 8 is proposed to estimate the rotating speed of the generator, $\omega_{\mathrm{g}}(\mathrm{rad} / \mathrm{second})$, given by Equation 1 . The current and voltage output of the rectifier is measured. From the knowledge about the generator specifications the speed is determined.

$$
\omega_{g}=\frac{2 \pi\left(V_{d}+2 R_{s} I_{d}\right)}{60\left(\frac{3 \sqrt{3}}{\pi} K_{m}-\frac{p}{2} L_{s} I_{d}\right)}
$$

The values of the other parameters are $\mathrm{R}_{\mathrm{s}}=0.1764 \mathrm{ohm}$, $\mathrm{L}_{\mathrm{s}}=0.835 \mathrm{mH}, \mathrm{K}_{\mathrm{m}}=1.4 \mathrm{~V} / \mathrm{rpm}$. Kopt is constant which includes Copt and $\lambda$ opt. Number of poles is 8, DC link voltage is $720 \mathrm{~V}$, rated frequency is $50 \mathrm{~Hz}$. Figure 9 represents Equation 1 in MATLAB.

The reference power is assessed by Equation 2 .

$$
P_{g}^{*}=K_{o p t}\left(\omega_{g}\right)^{3}
$$

Hence, DC voltage is estimated as in Equation 3.

$$
V_{d c}^{*}=\frac{P_{g}^{*}}{I_{d c}}
$$

The ANN was trained to identify input-output relationships. The developed wind turbine model is used to collect the training data comprising of PMSG voltage, current and duty ratio which is then used to train the system. The speed of the wind varies between $6 \mathrm{~m} / \mathrm{s}$ to $12 \mathrm{~m} / \mathrm{s}$.

The proposed ANFIS uses Sugeno inference mechanism. Figure 10 is a screen shot of the ANFIS editor. It shows a plot of the training error values. The ANFIS is generated with grid partitioning fuzzy inference mechanism, where each input is assigned seven membership functions and then trained for 3000 epochs (number of iterations for training) using hybrid learning rule. Figure 11 represents ANFIS with Sugeno inference system. Figure 12 gives the structure of ANFIS and parameters used in its execution process. In Figure (Structure Figure) 'input' represents the inputs which are change in error and error.

The proposed ANFIS controller reduces the settling time and overshoots in the system. This will enhance the system performance when compared to the conventional controllers. The results are as summarized in Table 2. 


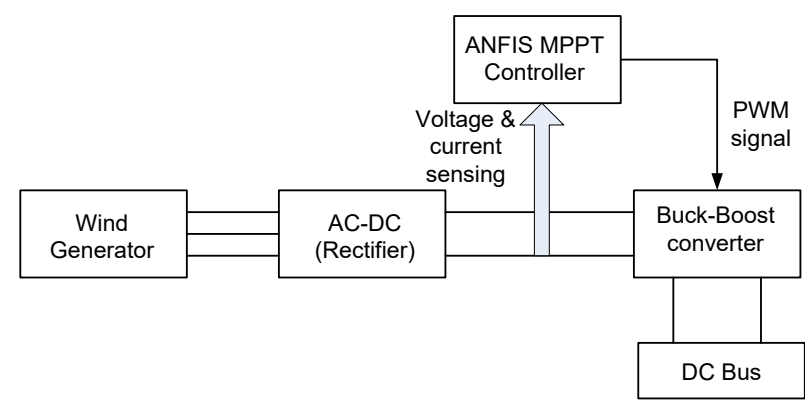

Figure 7. ANFIS based MPPT for wind energy system.

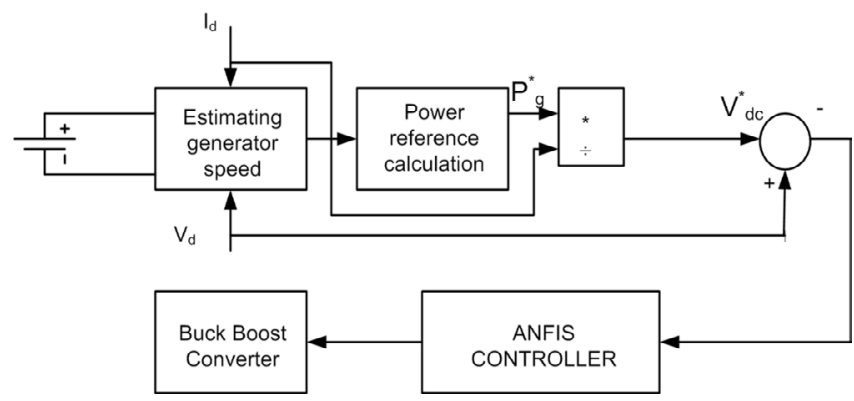

Figure 8. ANFIS based control strategy for MPPT.

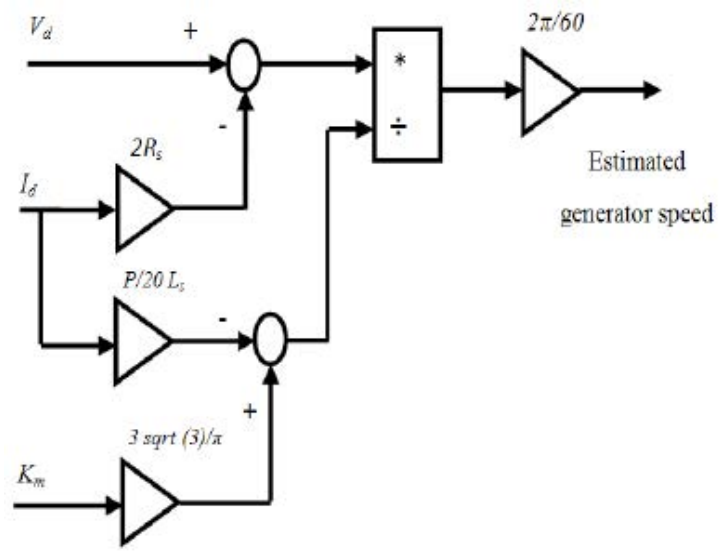

Figure 9. Generator speed estimation.

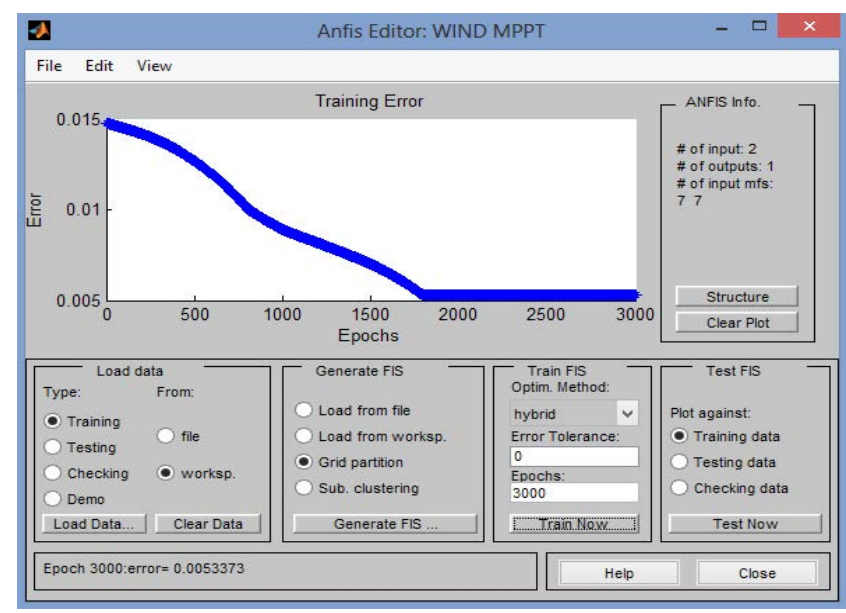

Figure 10. A screen shot of ANFIS editor for wind model.

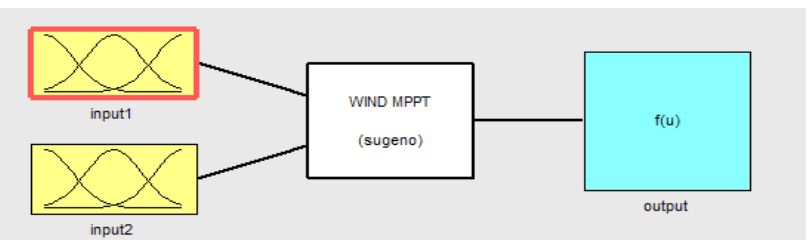

Figure 11. A Block representation of ANFIS for wind.

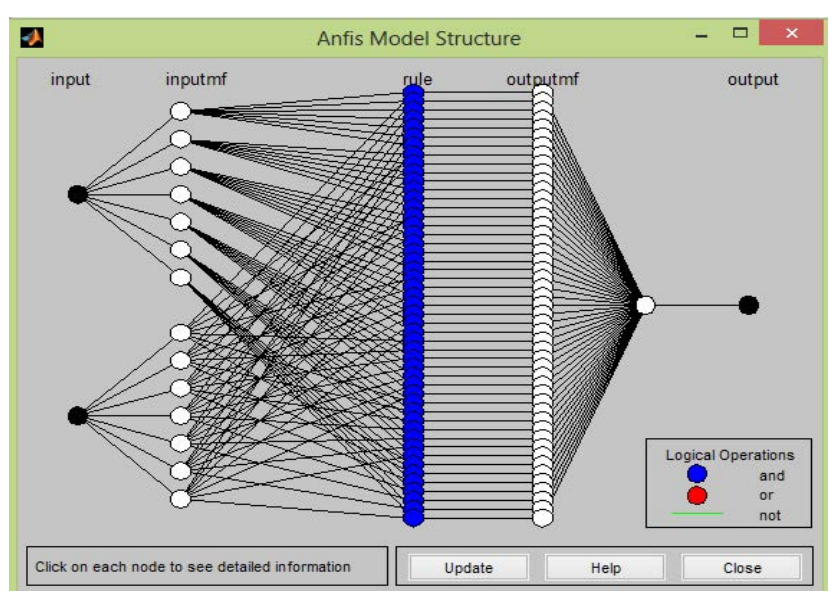

Figure 12. Structure of ANFIS for Wind

Table 2. Summary of results of power with conventional PI, fuzzy and ANFIS controllers.

\begin{tabular}{|l|l|l|l|}
\hline Parameter & PI & FUZZY & ANFIS \\
\hline Peak Overshoot (\%) & 11 & 10.8 & 3.9 \\
\hline Settling Time (seconds) & 0.8 & 0.65 & 0.5 \\
\hline
\end{tabular}

\section{Experimental Results}

The above system is simulated with conventional designs, their fuzzy counterparts and further with Adaptive Neuro Fuzzy counterparts. The outcome of the suggested ANFIS is related by means of fuzzy and PI controllers. The simulation results are shown in Figures 13 and 14.

\section{Conclusion}

The technological development and the increased power demand have led to harness of energy by hybrid method. This work is concerned with the use of intelligent controller solutions for extracting maximum power in solar-wind hybrid system. PMSG is used as a wind generator due to its self-excitation capabilities and requires less maintenance. A model was developed for an $8 \mathrm{~kW}$ output power using MATLAB/Simulink. A $3 \mathrm{KW}$ PV module is modelled and simulated for varying temperature and irradiations. The 


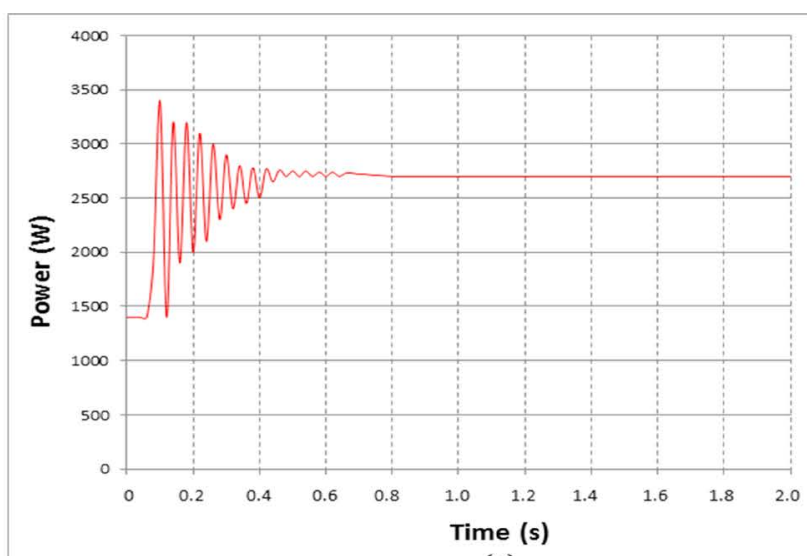

(a)

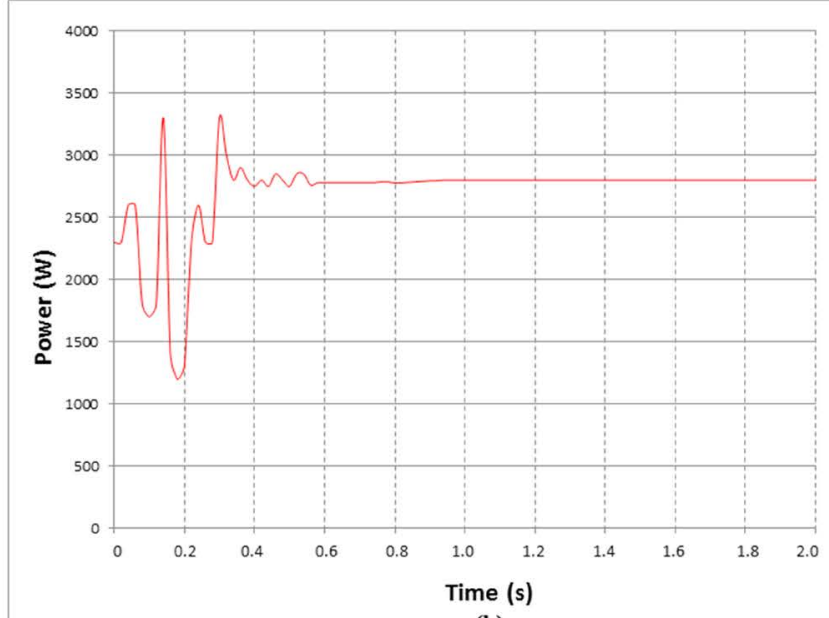

(b)

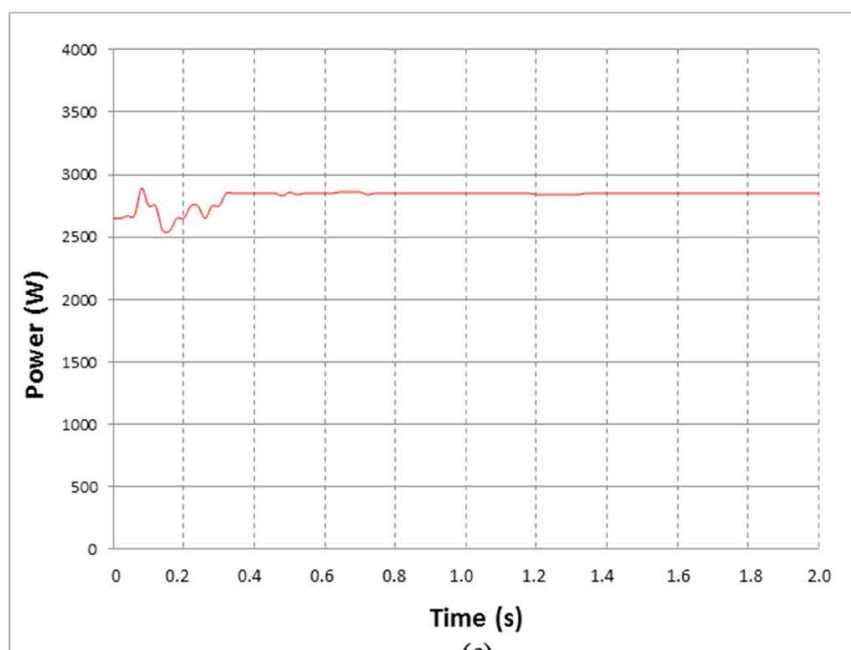

(c)

Figure 13. Simulation response of solar (a) PI (b) Fuzzy and (c) ANFIS controller.

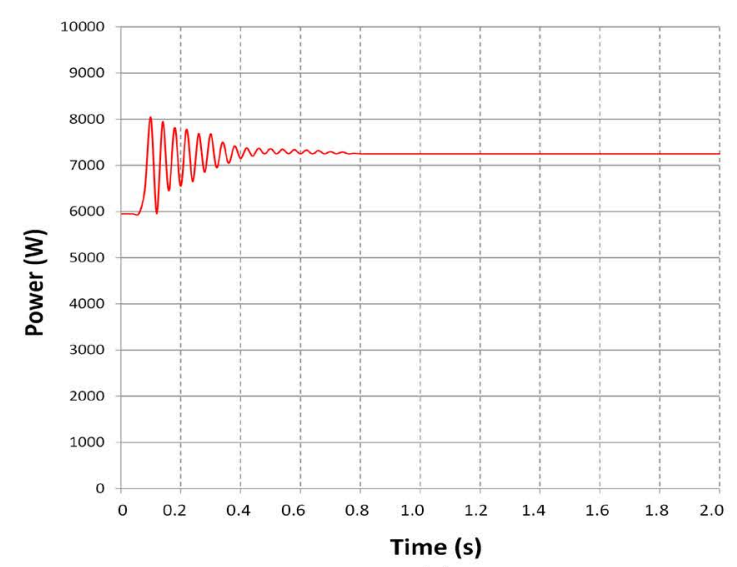

(a)

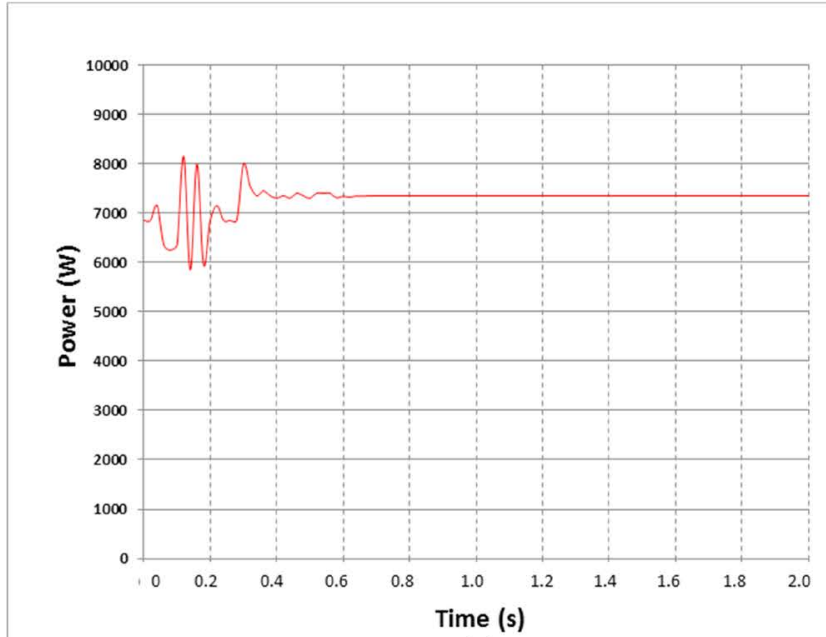

(b)

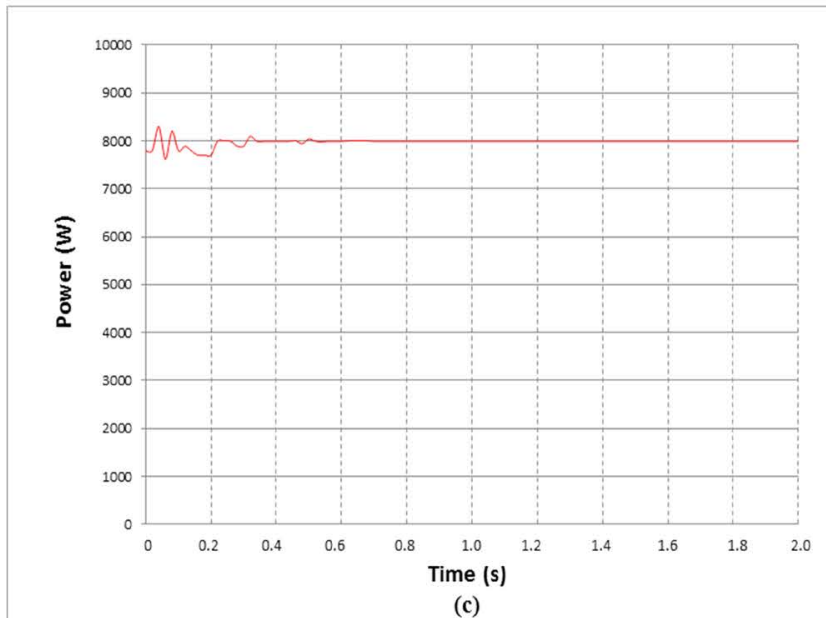

Figure 14. Simulation response of wind, (a) PI (b) Fuzzy and (c) ANFIS controller. 
conventional MPPT method is replaced with fuzzy and ANFIS counterparts. The results are equated in terms of robustness, precision and ease. The results of the projected system have small settling time and stumpy overshoot.

\section{References}

1. Rezk H, Eltamaly AM. A comprehensive comparison of different MPPT techniques for photovoltaic systems. Solar Energy. 2015; 112:1-11. https://doi.org/10.1016/j.solener.2014.11.010

2. Esram T, Chapman PL. Comparison of photovoltaic array maximum power point tracking techniques. IEEE Transactions on Energy Conversion. 2007; 22(2):439-49. https://doi.org/10.1109/TEC.2006.874230

3. Pandiarajan N, Muthu R. Mathematical modeling of photovoltaic module with Simulink mathematical modeling of photovoltaic module with Simulink. 1st International
Conference on Electrical Energy Systems; 2011. p. 3-5. https://doi.org/10.1109/ICEES.2011.5725339

4. Karthika J, Subbiah V, Kanthalakshmi S. Development of a supervisory controller for energy management and smooth operation of hybrid energy generation system with grid interface. Advances in Natural and Applied Sciences. 2016; 10(17):300-8.

5. Prakash S, Sinha SK. Load frequency control of multi-area power systems using neuro-fuzzy hybrid intelligent controllers. IETE Journal of Research. 2015; 61(5):526-32. https://doi.org/10.1080/03772063.2015.1024765

6. Karthika J, Subbiah V, Kanthalakshmi S. High performance supervisor controller with multimode operation of a hybrid system for multi grid applications. Middle-east Journal of Scientific Research. 2017; 25(2):296-303.

7. Tiwari SK, Singh B, Goel PK. Design and control of microgrid fed by renewable energy generating sources. IEEE 6th International Conference on Power Systems; 2016. p. 1-6. https://doi.org/10.1109/ICPES.2016.7584153 